\title{
THE VERTICAL COSEISMIC DEFORMATION FIELD OF THE WENCHUAN EARTHQUAKE BASED ON THE COMBINATION OF GPS AND INSAR
}

\author{
SHAN Xin-jian ${ }^{(1)}$, QU Chun-yan ${ }^{(1)}$, GUO Li-min ${ }^{(1,2)}$, ZHANG Guo-hong ${ }^{(1)}$, SONG Xiao-gang ${ }^{(1)}$, JIANG Yu $^{(1,3)}$, \\ ZHANG Gui-fang ${ }^{(1)}$, WEN Shao-yan ${ }^{(1,4)}$, WANG Chi-sheng ${ }^{(1,5)}$, XU Xiao-bo ${ }^{(1)}$, LIU Yun-hua ${ }^{(2)}$

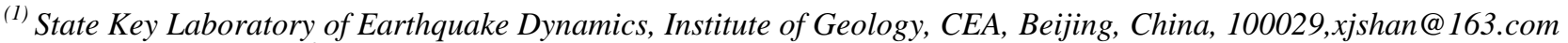 \\ ${ }^{(2)}$ Institute of seismology, Wuhan, China, 430071, lim_guo@hotmail.com \\ ${ }^{(3)}$ China university of petroleum (Huadong), Qingdao, China, 266580,jyqingdao@gmail.com \\ ${ }^{(4)}$ Seismological Bureau of Xinjiang Uyger Autonomous Region, Urumqi, China, 830011, wenshaoyan999@163.com \\ ${ }^{(5)}$ Shen Zhen University, Shen Zhen, China, 518060,wangchisheng@163.com
}

\begin{abstract}
Vertical coseisimic deformation near seismogenic fault provides meaningful information for understanding of rupture characteristics of the seismogenic fault and focal mechanism. Taking Wenchuan thrust earthquake for an example, we interpolate GPS horizontal observed deformation using Biharmonic spline interpolation and derive them into East-Westward or North-Southward deformation field. We first use reliable GPS observed value to correct InSAR reference point and to unify both GPS and InSAR coordinate frame, and then obtain a continuous vertical deformation field by combined calculation of GPS and InSAR LOS deformation field. The results show that the vertical deformation of both hanging wall and foot wall of the fault decreases rapidly, with deformation greater than $30 \mathrm{~cm}$ within $50 \mathrm{~km}$ across the fault zone. The uneven distribution of the vertical deformation has some peak values at near fault, mainly distributed at the southern section (Yingxiu), the middle (Beichuan) and the northern end (Qingchuan) of the seismogenic fault.
\end{abstract}

\section{INTRODUCTION}

Surface coseismic deformation is a kind of threedimensional deformation. The strike slip fault appears mainly horizontal deformation, and thrust or normal fault appears mainly vertical deformation. Currently, observation methods, such as InSAR, GPS and level are mainly based on certain deformation observation. Therefore, the application of multiple means of observation data for solving surface coseismic deformation field's components, is significant to understand the movement pattern of fault, rupture characteristics and to analyze focal mechanism.

InSAR is a kind of side view deformation measurement technology. The deformation value radar obtains are projection in Radar line of sight (LOS) of surface in east-westward (EW), north-southward (NS) and vertical (up) deformation field. Since the surface deformation value it observes is one-dimensional, and unreliable to reflect true surface deformation, it causes a fuzzy problem in LOS of InSAR interferometry. It is difficult to separate horizontal and vertical deformation value merely by InSAR observation, and how to decompose deformation value of three directions from InSAR LOS deformation field has become a significant research area. There are some kinds of methods for solving coseismic crustal 3D deformation field nowadays: (1) Calculating three-dimensional deformation by InSAR in multi-line of sight direction. It uses radar satellite data of 3 different incident angles in descending or ascending track, and obtains deformation components in different line of sight of coseismic deformation field of one earthquake, to realize the solution of three-dimensional deformation field (Wright et al., 2004). The disadvantage is that radar data is unnecessarily incomplete of the same earthquake with the different direction before and after the earthquake. (2) Using InSAR deformation value in two different LOS directions, combined with the azimuth deformation field obtained by offset to calculate 3D coseismic deformation field (Fialko et al., 2001). Since the offset method is proposed in the light of large scale deformation, the combination of these two cannot guarantee the accuracy. (3) Using InSAR deformation value in two different LOS directions, combined with model deformation field in NS direction to calculate 3D deformation (Wang et al., 2009). But this method is not only restricted by strike and deformation direction of fault, but also affected by the adoption of model deformation components, making observation prematurely be interfused with theory analogy, and causing horizontal measurement unreliability. (4) Using GPS horizontal observation data and InSAR data in LOS direction to obtain 3D coseismic deformation field (Gudmundsson et al., 2002; Samsonov \& Tiampo, 2006). InSAR has the advantage of continuous covering in near field and high precision in LOS direction, and has become one of the most important methods to study earthquake coseismic deformation. GPS horizontal observation has the advantage of covering large area and is of high accuracy, so it has been widely applied to various scales of crustal movement observation and study of tectonic deformation. This method makes full use of the high precision of GPS horizontal observation, high accuracy of InSAR in line of sight direction and sensitivity in vertical direction, which combines discrete GPS observation point with InSAR data in continuous 
surface. But the disadvantage is that it requires high dentist GPS observation point, and needs to select suitable interpolation method.

The Wenchuan earthquake fault (Longmenshan fault) is overthrust nappe tectonic deformation zone in large scale, and it is mainly reverse charging (Deng et al., 1994; Zhang et al, 2008). The coseismic deformation on two sides of the fault has a big vertical movement component. In early times, the study of Wenchuan earthquake coseismic deformation field is mostly based on GPS horizontal observation (Zhang et al, 2008; Shen et al., 2009; Wang et al., 2011) and InSAR observation in LOS direction near fault (Shan et al., 2008), and horizontal observation(Wang et al, 2008). These observations have positive effects on understanding Wenchuan earthquake fault deformation characteristics. Since Wenchuan earthquake is dominated by thrusting, the acquisition of coseismic vertical deformation field is significant to understand characteristics and spatial distribution of 3D deformation in Longmenshan fault. In this paper, we take Wenchuan earthquake as an example, and obtain the slant range coseismic deformation field by InSAR, combining with GPS horizontal coseismic observation, to acquire continuous vertical deformation field of Wenchuan earthquake.

\section{DATA ACQUISITION AND COLLECTION OF DEFORMATION OBSERVATION}

\subsection{InSAR coseismic deformation field in slant direction of Wenchuan earthquake}

We derive coseismic deformation field of Wenchuan earthquake, by making use of ALOS/PALSAR image before and after the earthquake (Fig. 1). As we can see, the entire range of coseismic deformation field covers Wenchuan earthquake of $400 \mathrm{~km} * 500 \mathrm{~km}$. Considering the satellite's ascending track, blue negative region stands for being far away from the satellite, yellow positive region stands for being near the satellite. In another word, the hanging wall of the fault mainly moves eastward, with the displacement of about -110 $120 \mathrm{~cm}$; the footwall mainly moves westward, with the displacement of about 120 130cm.

The observational result of InSAR deformation is in line of sight, and is the projection in LOS direction of horizontal deformation (EW or NS) and vertical deformation. Therefore, InSAR observation value is only one-dimensional surface variables, and is difficult to recognize and analyse vertical deformation and features from coseismic deformation field of Wenchuan. The seismogenic fault of Wenchuan earthquake is mainly in reverse thrust, and deformation in near field should be big, which is of significance to understand deformation characteristics of Wenchuan earthquake seismogenic fault.

\subsection{GPS coseismic deformation observation data of Wenchuan earthquake}

Wang et al. (2011) collected comprehensive GPS coseismic observation data of the earthquake, including continuous station, flow station, and triangulation station. Furthermore, they supplied 42 results of level measurement. As we can see, $57 \%$ of GPS observation points are located in InSAR observing area, which makes it possible for correcting InSAR data and interpolating GPS results. And all of the horizontal observation points are within InSAR observing area as well.

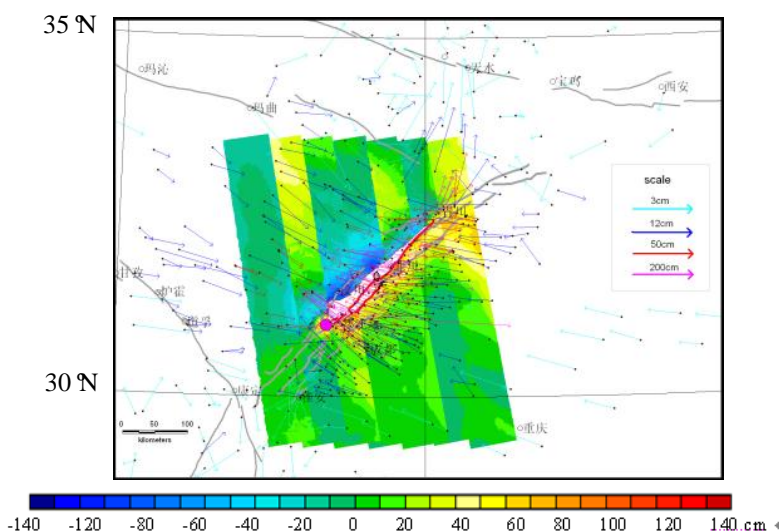

Figure 1. Horizontal displacement of Wenchuan earthquake measured by InSAR and GPS (Red lines and grey lines are surface ruptures produced during the Wenchuan earthquake and active faults, respectively. Arrows represent different scales GPS observed horizontal displacement.)

\section{RESEARCH IDEAS IN VERTICAL DEFORMATION FIELD OF WENCHUAN EARTHQUAKE}

Taking high precision and dense distribution of GPS and InSAR measurement into account, we combine horizontal measurement by GPS and LOS deformation by InSAR to derive vertical coseismic deformation.

(1) Make Biharmonic spline interpolation for GPS horizontal measurements, including both its magnitude and direction, and then deformation field is decomposed into EW and NS directions.

(2) In order to reduce the spatial resolution, make resampling on InSAR deformation field in the line of sight direction.

(3) Since InSAR and GPS measurements are derived in different coordinate system, it is necessary to correct InSAR measurement by GPS measurement, which will be propitious to compose and decompose 3D deformation field. Considering that unwrapping is applied on hanging wall and foot wall respectively, correction for InSAR should be applied on two walls respectively as well, followed by splicing into the entire InSAR line of sight deformation field. 
(4) By adopting 3D deformation field decomposition model, we can derive the vertical coseismic deformation field of the wenchuan earthquake, based on the combination of GPS, both in EW and NS direction above and corrected InSAR line of sight deformation.

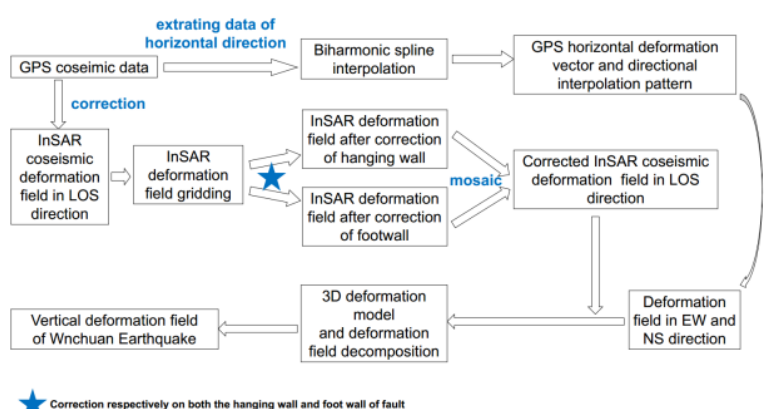

Figure 2.Flowchart process deriving the vertical coseismic deformation of the Wenchuan earthquake

\section{DATA PROCESSING FLOW}

\subsection{Correction of InSAR deformation in LOS}

Due to the deformation field observed by InSAR is unwrapping independently relative to each edge of the strip, and GPS observation results are relative to the Eurasian plate, therefore, it is necessary to use GPS observation points as reference points to correct InSAR observation, so InSAR and GPS observations are in the same reference frame, making it convenient to synthetise and decompose 3D deformation field. Before correction, we resample InSAR coseismic deformation field in line of sight direction, and reduce its spatial resolution. Considering the high point density of InSAR observation data, and scare GPS observation points, we resample for each of the InSAR bands to reduce computational time, and each strip grid point is $512 * 1024$ after resampling; secondly, due to the hugeness of deformation gradient in the Longmenshan fault zone, resulting serious loss of correlation in InSAR observation. The InSAR band unwrapping in meizoseismal area is divided respectively by hanging wall and foot wall of fault. Therefore, when correcting InSAR data using GPS reference points, correction must also be carried out on hanging wall and foot wall respectively. When selecting GPS reference points, if observation value of certain GPS point is greater than 2 times of residual, this point should not be adopted as a calibration point. In this way, each InSAR band can still be kept enough GPS observation points on the hanging or foot wall. So InSAR and GPS offset of high precision can be calculated. Fig. 3 shows the comparative map of InSAR deformation field in line of sight before and after correction.

Through comparative analysis of Fig. 3(a) and Fig. 3(b), we can find that the consistency among deformation field bands is improved through correction. Such as in the northern section of 476 track, the deformation value has decreased after correction and becomes close to the deformation value of the strip 475 , which is adjacent with strip 476. In the upper left corner of the image, the deformation value is too large for strip 471 before correction, and the corrected deformation value is close to 472 track.

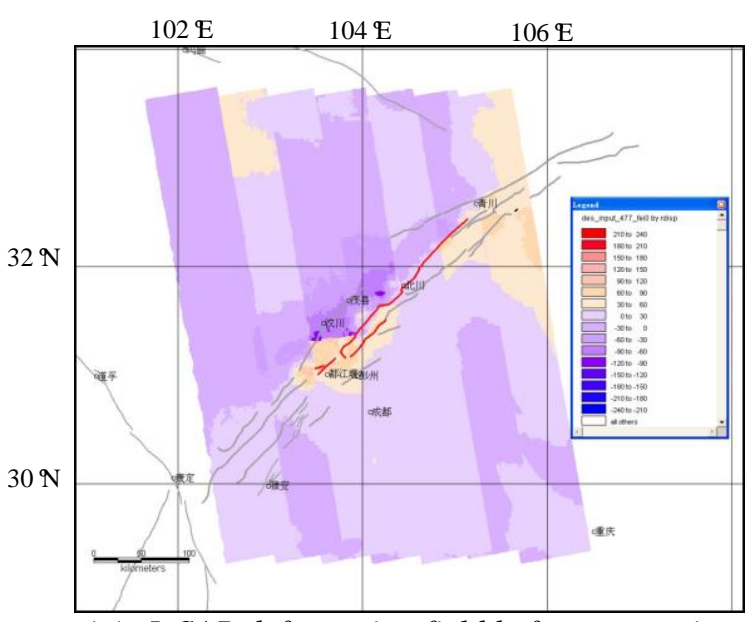

(a) InSAR deformation field before correction

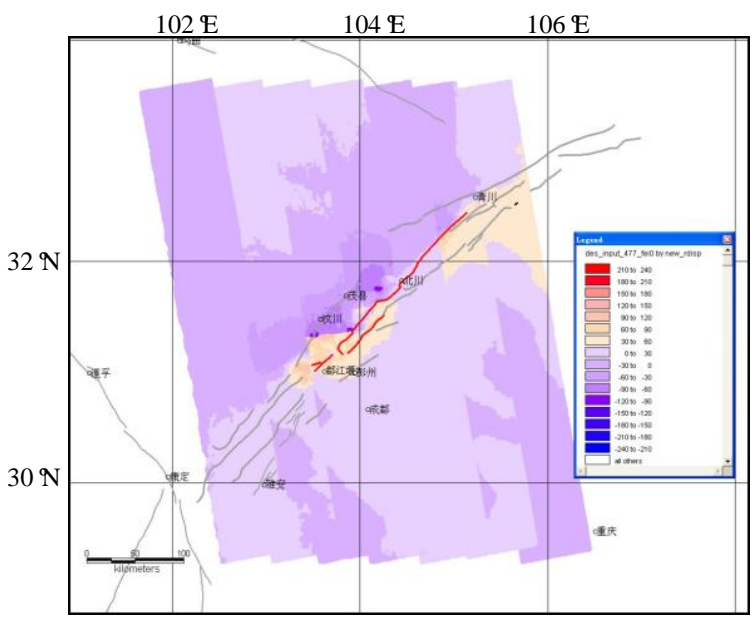

(b) InSAR deformation field after correction

Figure 3. Comparison of uncorrected and corrected of InSAR LOS deformation (Red lines and grey lines are surface ruptures produced during the Wenchuan earthquake and active faults, respectively.)

Fig. 4 shows the profile comparison chart before and after correction of InSAR and GPS observation deformation from south to north, take band 475 as an example. 475 track includes 61 GPS observation points, where 19 on the hanging wall, and 42 on the foot wall. First of all, we project the GPS observed EW, NS, UP component value to LOS direction, in another word, to calculate the deformation value of GPS observation in LOS direction. Secondly, we compare them with the measurements of InSAR. The standard deviation of GPS and InSAR is 44.4 on the hanging wall of the fault, and 
the foot wall is calibrated as 12.2. We pick GPS points less than 2 times of the standard deviation, after screening, there are 18 GPS points on the hanging wall, and 40 on the foot wall. The mean D-value of GPS and InSAR observations on the hanging wall is $9.93 \mathrm{~cm}$, and the value is $-11.49 \mathrm{~cm}$ on the foot wall, these two values are offset constant that need to be corrected for InSAR observation. After correction, the average difference is $0.005 \mathrm{~cm}$ between GPS and InSAR observation on the hanging wall, the standard deviation is reduced to 19.09; the average difference is $-0.004 \mathrm{~cm}$ between GPS and InSAR observation on the foot wall, and the standard deviation is reduced to 5.1. We can see that the consistency of InSAR and GPS is improved through correction.

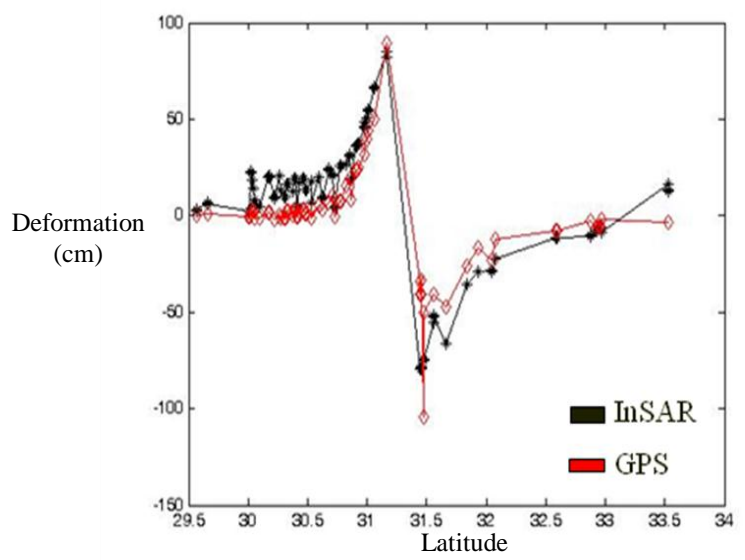

(a) Comparison of uncorrected InSAR and GPS

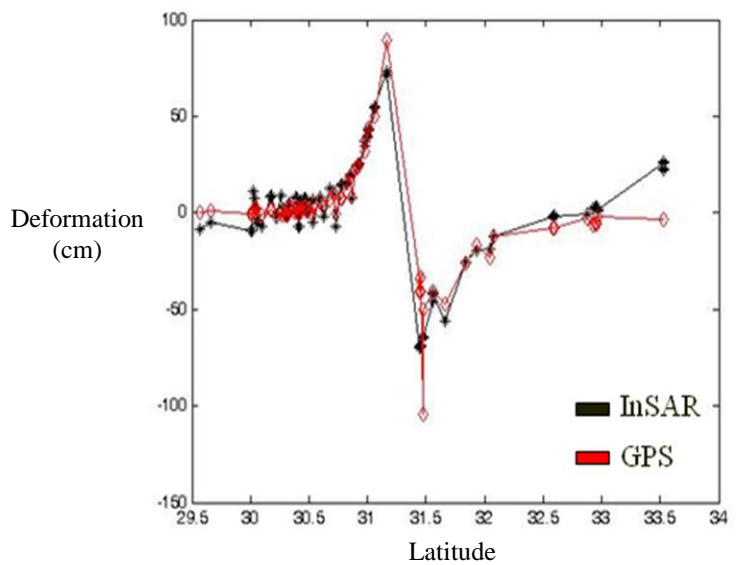

(b) Comparison of corrected InSAR and GPS

Figure 4.Profiling comparison of uncorrected and corrected InSAR and GPS along 475 track

\subsection{Methods and results of interpolation for GPS horizontal observation}

Taking characteristics of GPS coseismic horizontal deformation into account, we adopt the Biharmonic spline interpolation to interpolate GPS horizontal observed deformation vector (both magnitude and direction of horizontal displacement) for three reasons: (1) The magnitude and direction of GPS horizontal observed vector, shall change continuously and orderly on hanging or foot wall of seismic fault. (2) In terms of deformation, the seismogenic fault belongs to the discontinuity plane, which means the direction of deformation vector on two walls is opposite. Luckily, this method can solve the problem of discontinuity plane, and is in accordance with physical characteristics on both walls of seismogenic fault. (3) GPS stations are distributed randomly and discretely, and yet there is no requirement about distribution of GPS for control points.

Biharmonic spline interpolation has three characteristics as follows: (1) Biharmonic spline interpolation is a minimum curvature surface interpolation, as this method could make use of not only the value of each point but also the slope to generate curved surface. Since curved surface satisfy the Biharmoic equation, local smoothness of interpolation result turn out well. (2)The result of interpolation is the liner combination of Green function centring on each data point, and the solution of Biharmonic equation in different dimensional space is the Green function in different dimension. (3) The number of Green function is less than that of data points, which will not make the interpolation result match the imprecise data points (Sandwell et al., 1987; Li et al., 2011; Lu, 2011; Wang et al., 2007).

For $\mathrm{N}$ data points $P_{\mathrm{i}} \quad(\mathrm{i}=1 \sim \mathrm{N})$, the problem of Biharmonic spline interpolation is turned into solving Eq.1:

$$
\begin{gathered}
\nabla^{4} \omega(P)=\sum_{j=1}^{N} a_{j} \phi\left(P-P_{j}\right) \\
\omega\left(P_{\mathrm{i}}\right)=\omega_{\mathrm{i}}
\end{gathered}
$$

Where $\nabla^{4}$ is the biharmonic the operator, and $\varphi(P)$ is the Green function in 2D space, $\varphi(P)=|P|^{2}[(\ln P-1)]$. $\mathrm{P}$ is the location of one point in the plane, and $\omega(P)$ is the deformation where $\mathrm{P}$ is located. The general solution of (1) is

$$
\omega(P)=\sum_{j=1}^{N} a_{j} \varphi\left(P-P_{\mathrm{j}}\right)
$$

$a_{j}$ is found by solving the liner system.

$$
\omega\left(P_{i}\right)=\sum_{\mathrm{j}=1}^{N} a_{j} \varphi\left(P_{i}-P_{j}\right)
$$

When $i=j$ in Eq.3, let RSH be equal to 0, like $a_{\mathrm{j}} \varphi\left(P_{j}-P_{j}\right)=0$. 
At first, we input coordinate $P_{i}\left(x_{i}, y_{i}\right)$ and deformation $\omega\left(P_{i}\right)$ of $\mathrm{N}$ deformation observation point in Eq.3 and build the system of liner equations consist of $\mathrm{N}$ deformation observation point $\mathrm{Pi}$. And then calculate by solving the system of liner equation. Finally, we can derive the deformation of interpolated point by Eq. 2 .

We take advantage of the high precision of GPS horizontal observation, make use of Biharmonic spline interpolation to interpolate GPS horizontal deformation both in magnitude and direction, and derive horizontal deformation vector field with high precision. Fig. 5 shows the result of interpolation for GPS deformation field in EW and NS direction.

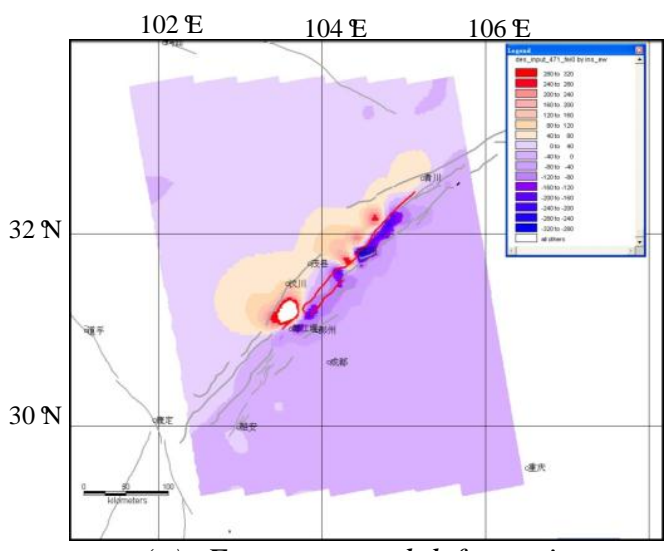

(a) East-westward deformation

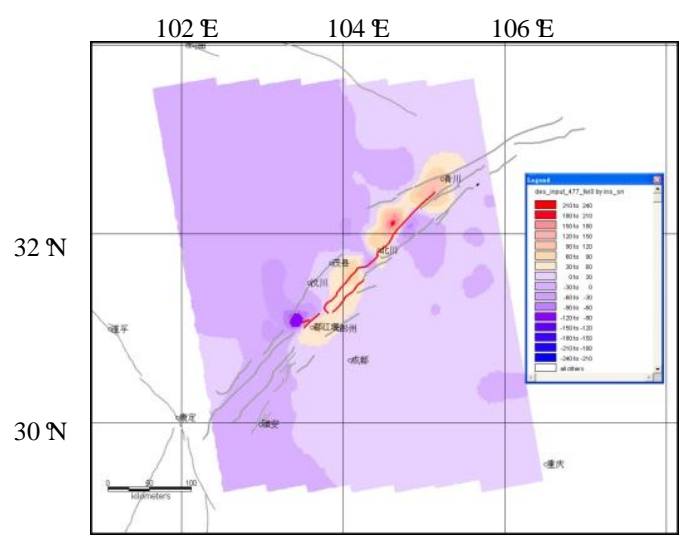

(b) North-southward deformation

Figure 5. East-westward and North-southward deformation after interpolation based on GPS measurements (Deformation range of the white area in Fig. 5 is $240-585 \mathrm{~cm}$ )

Compared with discrete GPS observation points, the deformation field image (Fig. 5) can reflect the variation characteristics of surface continuous deformation field better. In Fig. 5(a), red and yellow order stands for positive value, which means that the crust is moving to the east. Blue and purple order stands for negative value, which means that the crust is moving to the west. As can be seen, the thrust component of Longmenshan seismogenic fault decrease gradually from south to north and the main thrust deformation is concentrated in Yingxiu-Lianshanping and Chaping-Beichuan-Nanba sections. At the same time, there appears eastward displacement maximum region (white area) in the town of Yingxiu-Lianshanping, and the eastward displacement reached $585 \mathrm{~cm}$ on the hanging wall of the fault, while the westward displacement is about $100 \mathrm{~cm}$ on the foot wall. In the section of Chaping-Beichuan county, the westward displacement reached $-280 \mathrm{~cm}$ on the foot wall of the fault, and the eastward displacement is $290 \mathrm{~cm}$ on the hanging wall. The eastward movement is absolutely dominant on the hanging wall in southern section of the seismogenic fault, and in the north and central section of the seismogenic fault, it is mainly converted to hedge displacement on the foot wall of seismogenic fault.

In Fig. 5(b), red and yellow order stands for positive value, which means that the crust is moving to the north. Blue and purple order stands for negative value, which means that the crust is moving to the south. As can be seen, the south section of the seismogenic fault obviously moves northward, and there is certain dextral strike slip component. The north displacement component reaches $185 \mathrm{~cm}$ in the Qiaotou area, while reaches $125 \mathrm{~cm}$ in the south of Qingchuan.

\subsection{The decomposition of $3 D$ deformation observations}

The deformation obtained by InSAR cannot represent the real deformation, but the projection of surface east and west (EW), south and north (NS) and vertical (U) deformation component in radar line of sight (LOS). So we can get the relationship between them. As is shown in Fig. 6, $\theta$ is an incident angle for satellite centre, $\alpha$ is an intersection angle between satellite flight direction (Heading direction) and north direction (clockwise), and $\alpha-3 \pi / 2$ is the range of sight direction (Azimuth Look Direction, abbreviated as ALD), which means the intersection angle between the distance direction and the north direction.

According to the geometric relations of InSAR measurements and 3D deformation variables, and assuming that the deformation value $d_{l o s}$ in LOS is negative when targets are away from radar, and $d_{l o s}$ is positive when targets are close to radar, we can derive the relationship between the deformation variables in line of sight $\left(d_{l o s}\right)$ and real surface 3D deformation variables $\left(d_{U}, d_{N}, d_{E}\right)$ as follows:

$d_{\text {LOS }}=d_{U} \cos \theta-\sin \theta\left[d_{N} \cos (\alpha-3 \pi / 2)+d_{E} \sin (\alpha-3 \pi / 2)\right]$ 
From Eq.4 we can see that as long as we know three variables among $d_{l o s}, d_{U}, d_{N}$ and $d_{E}$, we can calculate the fourth one.

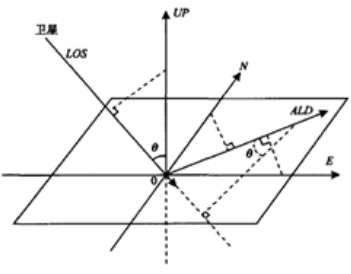

(a)

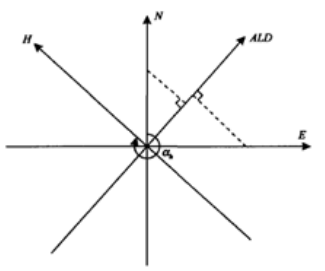

Figure 6. The geometry between InSAR line of sight observation and the geographical coordination

(ALD is range direction. $\theta$ and $\alpha$ are satellite incidence angle and the clockwise angle between satellite flight and due north direction, respectively.)

\section{RESULTS}

On the basis of deformation field $d_{N}$ and $d_{E}$ obtained by GPS interpolation in EW and NS direction in Fig. 5, as well as corrected InSAR deformation field $d_{l o s}$ in LOS direction in Fig. 3(b), we can calculate $d_{U}$ of the vertical co-seismic deformation of the Wenchuan Earthquake by using the Eq.4. The calculated vertical co-seismic deformation field of Wenchuan Earthquake has been shown in Fig. 7, covering the area of $400 \mathrm{~km} * 500 \mathrm{~km}$.

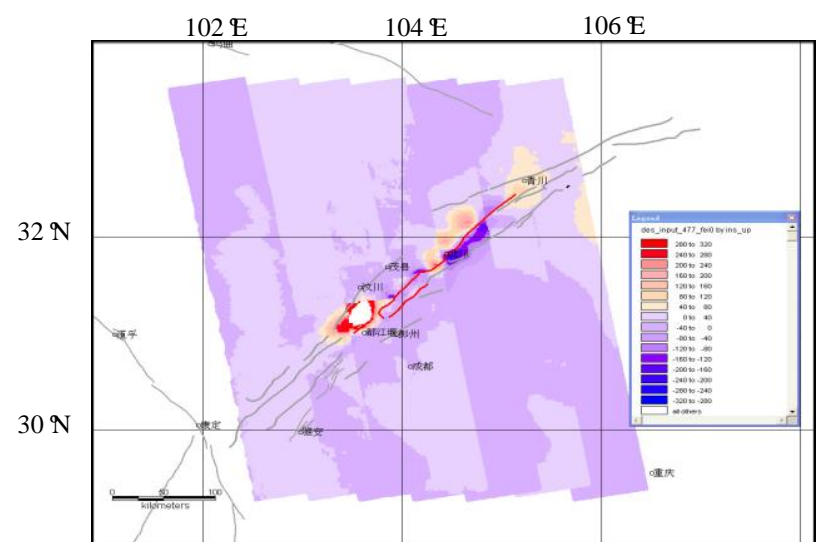

Figure 7. The derived Wenchuan earthquake coseismic vertical deformation (Vertical deformation range of the white area is $320-550 \mathrm{~cm}$ )

It can be seen from Fig. 7 that the vertical co-seismic deformation field has different deformation characteristics with slant-range co-seismic deformation field in Fig. 1 and with EW, NS direction deformation field in Fig. 5. In the terms of distribution, some characteristics have shown as follows: (1) The relative large vertical deformation is not distributed in both sides of seismogenic fault but segments of it, and mainly distributed in south section, the middle and northern part of Yingxiu-Beichuan seismogenic fault. (2) The vertical deformation of both fault sides decreases rapidly, the areas whose variation of vertical deformation is more than $30 \mathrm{~cm}$ are mainly distributed near the fault zone, and the sum distances to seismogenic fault of both hanging wall and foot wall are not more than $50 \mathrm{~km}$. That may be related to fault dip which is almost erect. (3) In the south section of seismogenic fault, the vertical deformation of both fault sides is extremely asymmetry, and mainly distributed on the hanging wall of the fault between the towns of Wenchuan and Dujiangyan, covering an area of $30 \mathrm{~km} * 40 \mathrm{~km}$, with the maximum uplifting reaching $5.5 \mathrm{~m}$ in the zone between Yingxiu town and Lianshanping, but the subsiding of the foot wall is smaller comparatively only $-0.6 \mathrm{~cm}$; in the middle section, the vertical deformation has shown a strong anti-asymmetry feature. In the zone of ChapingBeichuan-Nanba, the largest uplifting area on the hanging wall is located in eastern side of Chaping reaching around $255 \mathrm{~cm}$. The uplifting of Baini in the north of the Beichuan town reaches $185 \mathrm{~cm}$, and the subsiding of Yonqing on the foot wall is $-215 \mathrm{~cm}$. The uplifting of the hanging wall located in west of Qiaotou reaches $215 \mathrm{~cm}$, the subsiding of Xiangyan on the foot wall is $-190 \mathrm{~cm}$. In the northern end of seismogenic fault, the vertical deformation has shown a symmetry feature, with a large area of uplifting reaching $120 \mathrm{~cm}$ in the zone of Qingchuan. Shen et al. (2009) have studied slippage and co-seismic deformation of Wenchuan using GPS and InSAR data, showing that the slippage of fault in Yingxiu, Beichuan and Nanba, have reached the maximum, and the damage of ground caused by earthquake is the most serious. That result is consistent with vertical deformation field in this paper.

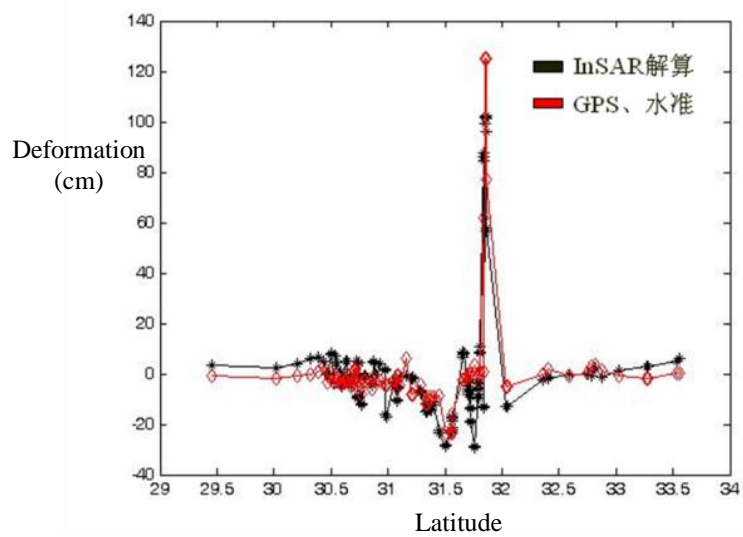

Figure 8.Comparison among the derived vertical deformation, GPS measurements, Leveling observation in profile

There are 88 GPS control points and bench marks in the 474 track, and 80 vertical observation values remained 
after removing values bigger than 3 times standard deviation, which can be compared with calculated vertical deformation value. The profile comparison map of calculated vertical deformation and vertical observation deformation by GPS and levelling has been shown in Fig. 8. As can be seen, the calculated vertical deformation by InSAR and the observation of GPS and leveling have roughly the same trend. The bigger vertical deformation is mainly located in the region near two sides of the fault. There are differences of about $4 \mathrm{~cm}$ on the foot wall far away from the fault zone. There are differences of deformation value about $5 \mathrm{~cm}$ far away from the fault zone on the hanging wall of the fault, but the performance was relatively stable. In the near fault, deformation fluctuates wildly, so there are significant differences between them. The maximum vertical displacement observed near the fault on level MB23 identification point reaches $124.99 \mathrm{~cm}$, at the same time the vertical displacement calculated from InSAR is $101.96 \mathrm{~cm}$, the difference between them is $23.03 \mathrm{~cm}$. In addition, in the vicinity of $31.7 \mathrm{~N}$, the vertical deformation calculated by the InSAR solutions reaches $-28 \mathrm{~cm}$, and the vertical displacement on the bench mark MB11 is $3.16 \mathrm{~cm}$, the difference between them is $31.9 \mathrm{~cm}$. The bigger difference of deformation value near the fault is caused by the reason that the low precision of data acquired or the loss of coherence.

\section{CONCLUSION}

Combining InSAR with GPS, not only can we improve observation accuracy, but also obtain more abundant information of deformation field on ground surface. InSAR deformation, with one-dimensional, is projected in the direction of sight by horizontal and vertical deformation. However, when there are plenty of GPS and leveling measurements, two of them could be decomposed in vertical deformation more reliably. We have noticed that:

(1) Make Biharmonic spline interpolation for GPS horizontal measurements both its magnitude and direction. In this paper we initially make interpolation in the magnitude and direction of parallel deformation vector of ground by using Biharmonic spine interpolation, and then derive them into EW and NS direction. Considering that the magnitude and direction of deformation vector on both the hanging wall and foot wall of the fault show an orderly and stable feature, which not only solve problems of disorder near discontinuity surface of fault deformation in the other calculation methods, but also more close to the real deformation features compared with direct interpolation in the EW and NS direction deformation.

(2) Reference point correction is necessary for the combined calculation of the GPS and InSAR, because they have different coordinate frame. Deformation reference point of InSAR is relative to the image itself, in the near field, while GPS is relative to the Eurasian plate, in the far field. For this case, a constant deviation exists between them. The correction of the InSAR reference point using GPS observations of the far field is needed for 3D deformation field synthesis or decomposition in the use of both data.

(3) The co-seismic vertical deformation field of the Wenchuan earthquake we got is consistent with research about the seismogenic fault deformation. Furthermore, we obtained some new knowledge. The vertical deformation of both hanging wall and foot wall of the fault decreases rapidly, with deformation greater than $30 \mathrm{~cm}$ within $50 \mathrm{~km}$ across the fault zone. Vertical deformation is uneven and its distribution is mainly concentrated in southern, middle and northern section of the seismogenic fault. These three segments have their own characteristics. The southern section of the fault has an obvious asymmetric feature, which exhibits dramatic uplift reaching $550 \mathrm{~cm}$ on the hanging wall, with the maximum uplift area in Yingxiu town to Lianshanping. The middle section shows a strong antisymmetric feature, with one side uplifting and the other subsiding. The largest uplifting of the southern segment reaches around $255 \mathrm{~cm}$, located at the east of Chaping and the largest subsiding is in Yongqing, reaching around $-215 \mathrm{~cm}$. The vertical deformation of the northern section is relatively smaller, only $120 \mathrm{~cm}$, in symmetrical distribution in north of Qingchuan, shown as 'the tail of a lion' hanging in the northernmost seismogenic fault.

\section{REFERENCE}

[1] Deng, Q. D., Chen, S. F., \& Zhao, X. L. (1994). Tectonics, seismicity and dynamics of Longmenshan Mountains and its adjacent regions. Seismology and Geology. 16(4), 389-403.

[2] Fialko, Y., Simons, M., \& Agnew, D. (2001). The complete (3-D) surface displacement field in the epicentral area of the 1999 Mw7. 1 Hector Mine earthquake, California, from space geodetic observations. Geophysical Research Letters. 28(16), 3063-3066.

[3] Gudmundsson, S., Sigmundsson, F., \& Carstensen, J. M. (2002). Three - dimensional surface motion maps estimated from combined interferometric synthetic aperture radar and GPS data. Journal of Geophysical Research: Solid Earth (1978 -2012). 107(B10), ETG-13.

[4] Li, Y. J., Luo, L. M., Zhang, P. C., Zhang, Q., \& Yang, C. S. (2011). Distortion correction of XR II image based on calibration grid characteristic and Biharmonic interpolation. Journal of Southeast University (Natural Science Edition). 41(6), 12131218. 
[5] Lu Peng. (2011). 3D terrain generation out of discrete data by Biharmonic spline method. $G X$ Water Risource \& Hydropower Engineering. 2011(6), 64-73.

[6] Qu, C. Y., Shan, X. J., Zhang, G. H., Song, X. G., \& Zhang, G. F. (2010). Coseismic displacement field of the Wenchuan Ms 8.0 earthquake in 2008 derived using differential radar interferometry. Journal of Applied Remote Sensing. 4(1), 043516-043516.

[7] Samsonov, S., \& Tiampo, K. (2006). Analytical optimization of a DInSAR and GPS dataset for derivation of three-dimensional surface motion. Geoscience and Remote Sensing Letters, IEEE. 3(1), 107-111.

[8] Sandwell, D. T. (1987). Biharmonic Spline Interpolation of GEOS-3 and SEASAT Altimeter Data. Geophysical Research Letters. 14(2), 139142.

[9] Shan, X. J., Qu, C. Y., Song, X. G., Zhang, G. F. Liu, Y. H., Guo, L. M., ... \& Li, W. D. (2009). Coseismic surface deformation caused by the Wenchuan Ms8. 0 earthquake from InSAR data analysis. Chinese Journal of Geophysics. 52(2), 496-504.

[10] Shen, Z. K., Sun, J. B., Zhang, P. Z., Wan, Y. G., Wang, M., Bürgmann, R., ... \& Wang, Q. L. (2009). Slip maxima at fault junctions and rupturing of barriers during the 2008 Wenchuan earthquake. Nature Geoscience. 2(10), 718-724.

[11] Wang, C. S., Shan, X. J., \& Zhang, G. H. (2009). 3D coseismic deformation field of the Yutian Ms 7.3 earthquake calculated from ASAR ascending and descending data. Earthquake. 29, 105-112.

[12] Wang, Q., Qiao, X. J., Lan, Q. G., Jeffrey, F., Yang, S. M., Xu, C. J., Yang, Y. L., You. X. Z., Tan, K., $\&$ Chen, G. (2011). Rupture of deep faults in the 2008 Wenchuan earthquake and uplift of the Longmen Shan. Nature Geoscience. 4(9), 634-640.

[13] Wang, Q. L., Cui, D. X., Zhang, X., Wang, W. P., Liu, J. W., Tian, K., \& Song, Z. S. (2008). Coseismic vertical deformation of the MS 8.0 Wenchuan earthquake from repeated levelings and its constraint on listric fault geometry. Earthquake Science. 22(6), 595-602.

[14] Wang, Y. T., Dong, L. F., \& Ni, K. (2007). Image morphing algorithm based on biharmonic spline interpolation and its implementation. Journal of Image and Graphics. 12(12), 2189-2194.

[15] Wright, T. J., Parsons, B. E., \& Lu, Z. (2004). Toward mapping surface deformation in three dimensions using InSAR. Geophysical Research
Letters. 31(1).

[16] Xu, X. W., Wen, X. Z., Yu, G. H., Chen, G. H., Klinger, Y., Hubbard, J., \& Shaw, J. (2009). Coseismic reverse-and oblique-slip surface faulting generated by the $2008 \mathrm{Mw} 7.9$ Wenchuan earthquake, China. Geology. 37(6), 515-518.

[17] Zhang, P. Z., Xu, X. W., Wen, X. Z., \& Ran, Y. K. (2008). Slip rates and recurrence intervals of the Longmen Shan active fault zone, and tectonic implications for the mechanism of the May 12 Wenchuan earthquake, 2008, Sichuan, China. Chinese Journal of Geophysics. 51(4), 1066-1073. 